\title{
CLIL. Content and Language Integrated Learning
}

Coyle, Do; Hood, Philip and Marsh, David. (2010) Cambridge: CUP.

Raquel Fernández Fernández

La presente publicación surge de la necesidad de profundizar en la enseñanza de contenidos y lengua adicional que se identifica bajo el acrónimo CLIL en inglés y AICLE en castellano. ${ }^{1}$ El volumen se divide en ocho capítulos que intentan tratar temas relativos tanto a la teoría como a la práctica de este tipo de enseñanza/aprendizaje. Así pues los autores comienzan delineando su contextualización y origen para pasar a la planificación. Posteriormente tratan el paso de la teoría a la práctica, el diseño y la adaptación de materiales y la evaluación del proceso de enseñanza/aprendizaje. Los dos últimos capítulos vuelven a ámbitos más generales. El primero de ellos trata la evaluación de programas CLIL y el segundo realiza una reflexión acerca del futuro de la enseñanza integrada desde una perspectiva social, cultural y económica.

En mi opinión, la publicación resuelve exitosamente las secciones dedicadas al contexto y a presentar las líneas generales del «enfoque». Los principios básicos del funcionamiento del mismo quedan aclarados, y la necesidad de su aplicación en la sociedad de nuestros días, y en la que ha de venir, queda justificada por diversos motivos, de los cuales destacaré dos. Por un lado la creciente necesidad de obtener una alta competencia comunicativa en otras lenguas aparte de la materna. Parece claro que la creciente movilidad en el mundo, y muy especialmente en el espacio europeo, junto con el uso cada vez más cotidiano de las nuevas tecnologías, hacen que la comunicación global sea un hecho, y que cada vez sea más necesario el aprendizaje de otras lenguas para reclamar nuestro sitio en la sociedad.

Otros de los motivos por los cuales queda justificada la adopción de un enfoque CLIL en el aula de contenido a través de una lengua extranjera es la actual necesidad de una

\footnotetext{
1 También existe el acrónimo AICOLE que la Comunidad de Madrid ha creado para describir la metodología empleada en el Proyecto Bilingüe iniciado en la región en 2004.
} 
enseñanza que se ajuste al modo de aprender de las nuevas generaciones. En palabras de los autores, las nuevas generaciones aprenden de un modo: «learn as you use, use as you learn» (p. 10), es decir, que el aprendizaje ya no se realiza como paso previo para poder ser llevado a la práctica después. El enfoque parece que podría satisfacer esta demanda. Además de esto, los autores justifican la utilidad del aprendizaje integrado desde una base neurológica, explicando, entre otras razones, que se estimula la flexibilidad cognitiva (p. 10).

Los capítulos intermedios, 4 y 5, pretenden ser una suerte de «caja de herramientas" para el profesorado. El punto de partida es el trabajo de Do Coyle referente a las 4 «ces» (4 Cs): comunicación, cognición, cultura y contenido. Para cada una de las dimensiones se incluye un mapa conceptual de guía, junto con numerosas preguntas que pretenden servir para que el docente vaya comprobando si ha cubierto todos los puntos importantes a la hora de abordar estas áreas, o para que reflexione sobre cuestiones que quedan abiertas según el contexto en que desarrolle su labor. También se ahonda en las tres dimensiones del lenguaje (lenguaje para el aprendizaje, del aprendizaje y a través del aprendizaje). Posteriormente (p. 66) se ofrece un mapa conceptual sobre el tema de los hábitats en el que se incluye la planificación general incluyendo tanto las 4 «ces» como las 3 dimensiones lingüísticas.

A mi modo de ver, estos capítulos, que se presentan como un «Tool Kit», no cuentan con muchos ejemplos concretos, y las herramientas que incluye son demasiado generales y se basan más en la propia reflexión del profesor que en ayudar a éste a reenfocar su enseñanza hacia lo que supone el uso de una lengua extranjera en la enseñanza de una asignatura de contenido. Quizás esta falta de concreción a la hora de dar pautas prácticas venga determinada por la propia naturaleza de la definición de CLIL. En otras palabras, al trabajar con la idea de «enfoque» los autores son demasiado cautos a la hora de aportar ideas prácticas. Probablemente intenten evitar dar pautas fijas de lo que podría ser una unidad didáctica CLIL para asegurarse de que no están «adoctrinando» a los lectores al uso de un único camino metodológico. A mi parecer, esto puede tener también el efecto contrario, es decir, el hecho de que no se determine claramente cuáles son las estrategias metodológicas que podrían asociarse con el enfoque CLIL, y que no se den varios, y ricos, ejemplos empleándolas, podría muy bien hacernos entrar en una «tierra de nadie», en donde cualquier estrategia didáctica sea válida.

En definitiva, no cabe la menor duda de que esta publicación es y será una referencia básica para cualquier persona involucrada en la enseñanza/aprendizaje de contenidos y lengua adicional. Es una excelente referencia para comenzar a ahondar en el enfoque 
CLIL, especialmente en lo referente a sus principios básicos y a su contextualización histórica y social. Por otro lado, la falta de concreción de este trabajo deja patente que todavía queda mucho por discutir, reflexionar y hacer. Es necesario pues seguir trabajando para y desde las aulas, delineando con claridad que son las «buenas prácticas», y surtiendo al profesorado de estrategias metodológicas que enriquezcan el trabajo (tanto en la teoría como en la práctica) con este enfoque metodológico. 